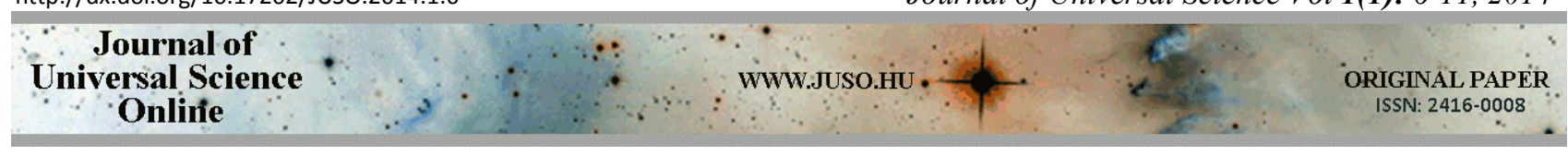

\title{
Differentiation of food spoilage yeast strains of the Yarrowia group by microsatellite polymerase chain reaction fingerprinting
}

\author{
Edina Szandra NAGY
}

National Collection of Agricultural and Industrial Microorganisms, Faculty of Food Science, Corvinus University of Budapest. Somlói út 14-16. H-1118 Budapest. Hungary.

Corresponding Author; Phone/Fax: +361/482-6247; e-mail: edina.nagy@uni-corvinus.hu

Received: 21 October 2014 / Revised: 12 November 2014 / Accepted: 17 December 2014

Keywords: microsatellite-PCR, Yarrowia, polymorphism

\begin{abstract}
Yarrowia lipolytica is a frequently reported food spoilage yeast which occurs mainly in meat and milk products. Besides its detrimental role in the food spoilage it has many favourable properties. This yeast also has been developed as a production host for a large variety of biotechnological applications. Some species of the Yarrowia group cannot be differentiated by conventional methods based on phenotypic characteristics, so it is probable that not only Yarrowia lipolytica, but also other species of the Yarrowia group contribute to food spoilage or can have a beneficial role in the industry. A relatively fast, easy and low-cost but reliable method would be useful to differentiate and identify these species properly.

Microsatellite PCR fingerprinting method is commonly used for the discrimination of species or strains within species, it is also applied for the identification of yeast species and in many yeast diversity studies, however, its reliability can be queried.

The aim of this study was to assess the reliability of microsatellite PCR fingerprinting using $(\mathrm{GAC})_{5}$ primer in the differentiation and identification of the yeast strains of the Yarrowia group by clustering them using microsatellite-PCR fingerprinting, then identifying them by sequencing the D1/D2 regions of the LSU rDNA of one or a few selected representatives of each cluster.

Two hundred and nineteen yeast strains of the Yarrowia group were examined.

Using this molecular biological method, yeast strains of the Yarrowia group from raw meat, raw milk, cheese and cottage cheese were assigned to seven species The food spoilage yeast strains of the Yarrowia group can be successfully differentiated by using microsatellite PCR fingerprinting method using (GAC) 5 primer, even their identity, thus their diversity can be assessed.
\end{abstract}

\section{Introduction}

Yarrowia lipolytica is a frequently reported food spoilage yeast which occurs mainly in meat and milk products [2]. Besides its detrimental role in the food spoilage many studies report its favourable contribution to the ripening and quality of cheeses $[3,11,20]$ and meat products [4, 16, 17, 19]. Yarrowia lipolytica has also been developed as a production host for a large variety of biotechnological applications, for example it has a high potential in the production of enzymes, organic acids, sugar alcohols, 


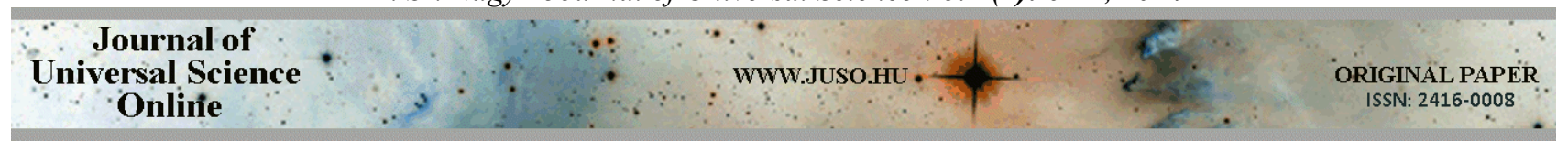

carotenoids and aroma compounds [5]. Some species of the Yarrowia group cannot be differentiated by conventional methods based on phenotypic characteristics $[8,9,10]$, so it is probable that not only Yarrowia lipolytica, but also other species of the Yarrowia group contribute to food spoilage or can have a beneficial role in the industry. A relatively fast, easy and low-cost but reliable method would be useful to identify these species properly.

Microsatellites have emerged as the marker of molecular genetic applications and found highly efficient in the DNA fingerprinting analysis due to their abundant and uniform distribution throughout the genome, highly variable nature with regard to repeat number, show codominant inheritance, ease of transferability and reproducibility [12]. Microsatellites are potentially the most informative molecular markers with the advantage of easy and low-cost detection by PCR due to their high mutation rate [6]. The amplified products are separated by electrophoresis to detect the polymorphism in repeat length [12].

This fingerprinting method is commonly used for the discrimination of species or strains within species [1]. It is also used for the identification of yeast species, many yeast

\section{Material and methods}

\section{Yeast isolates}

Over a period of three years 219 strains presumed as members of the Yarrowia group based on physiological tests were isolated from raw meat (66 samples), raw milk (40 samples) and dairy products such as cheese ( 9 samples) and cottage cheese (18 samples). Most of the meat samples were obtained from a quality control laboratory, some of them were purchased from supermarkets. Milk samples were obtained from farms or were purchased from dairy shops, milk products were purchased from supermarkets or diversity studies are based on clustering the yeast isolates using microsatellite-PCR fingerprinting, followed by identification of one or a few selected representatives of each cluster by sequencing [18].

However, the reliability of this method can be queried. Ramirez-Castrillon and co-workers (2014) evaluated a standardized protocol using microsatellite PCR fingerprinting for the discrimination of wine associated yeasts. They applied this technique to 245 strains, and compared the results with the identification obtained by partial sequencing of the LSU rRNA gene, considered as the gold standard. It was revealed that unrelated species were clustered in the same group. They concluded that the yeast diversity inferred in several previous studies may have been underestimated.

The aim of this study was to assess the reliability of microsatellite PCR fingerprinting using $(\mathrm{GAC})_{5}$ primer in the differentiation and identification of the yeast strains of the Yarrowia group by clustering them using microsatellite-PCR fingerprinting, then identifying them by sequencing the D1/D2 regions of the LSU rDNA of one or a few selected representatives of each cluster.

obtained from a quality control laboratory. All the samples originated from Hungary.

The isolation of the yeast strains was performed in three steps. First a three-step enrichment in a medium described by Nagy and co-workers (2013) was applied, followed by serial decimal dilutions and surface plating on Rose-Bengal chloramphenicol (RBC) agar. Finally cultures representing each colony type were isolated and purified by repeated streaking on glucose-peptone-yeast extract agar. 


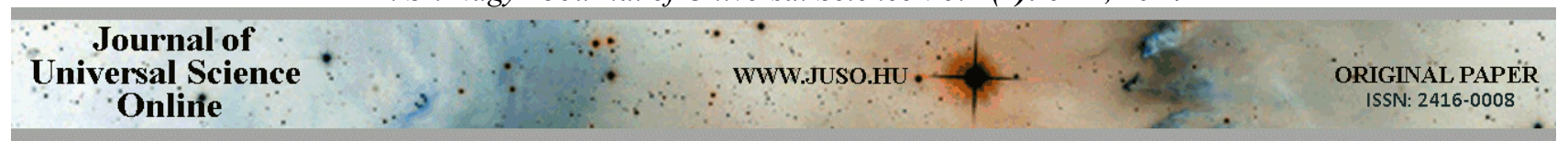

Members of the Yarrowia group were selected based on the results of physiological tests obtained by using API ID $32 \mathrm{C}$ tests (bioMérieux) and by examining their glucosefermentation, nitrate- and hexadecaneassimilation [15].

In this experiment, the type strains of the Yarrowia group were also used as reference.

\section{DNA extraction}

DNA was extracted from the strains by using Qiagen DNA extraction kit (Qiagen 69106, Switzerland), according to manufacturer's instructions.

\section{Microsatellite PCR fingerprinting}

A microsatellite primer $(\mathrm{GAC})_{5}$ was used in PCR amplification reactions from the DNA extracted from the strains. For amplification the following conditions were applied: initial denaturation at $95{ }^{\circ} \mathrm{C}$ for 3 minutes followed up by 30 cycles of denaturation $\left(96{ }^{\circ} \mathrm{C}, 30\right.$ seconds), annealing ( $59{ }^{\circ} \mathrm{C}, 35$ seconds) and extension $\left(73{ }^{\circ} \mathrm{C}, 55\right.$ seconds $)$. Amplification

\section{Results and discussions}

\section{PCR fingerprinting}

The resulting PCR products were separated by using horizontal agarose gel electrophoresis and stained with ethidium bromide then visualized by UV transillumination. They showed clear-cut polymorphism.

Strains were assigned to groups based on PCR fingerprinting, using the $(\mathrm{GAC})_{5}$ microsatellite primer and the above mentioned conditions. The 13 type strains showed 13 different fingerprints. The examined 219 strains, selected as members of the Yarrowia group based on their physiological characteristics formed seven groups by showing 7 different fingerprints. The identity of all of these strains could be assessed by comparing their fingerprints to the fingerprints of the type strains. was finished with a final extension at $72{ }^{\circ} \mathrm{C}$ for 30 seconds and cooling at $12{ }^{\circ} \mathrm{C}$. The PCR products were separated by horizontal agarose gel electrophoresis on $1.4 \%$ agarose gel, in 1X TAE buffer (0.04 M Tris-acetate, $0.001 \mathrm{M}$ EDTA - pH 8.0) at $5 \mathrm{~V} / \mathrm{cm}$ and stained with ethidium bromide $\left(7 \times 10^{-5} \mu \mathrm{g} / \mu \mathrm{l}\right)$. The resulting DNA fragments and the molecular size marker (Thermo Scientific, Generuler 100bp SM0321) were visualized by UV transillumination.

Amplification and sequencing of the D1/D2 region of the LSU rRNA gene

The D1/D2 domain of the large subunit (26S) rDNA from selected strains was sequenced as described by Kurtzman \& Robnett (1998). The amplicons were sequenced by commercial sequencing facilities (Bay Zoltán Nonprofit Ltd. for Applied Research, Hungary; or Biomi Ltd., Hungary). Sequence similarity searches were performed against the GenBank sequence database using the BLAST 2.2.28 database search program [21].

\section{Amplification and sequencing of the D1/D2 region}

To confirm the identity of the strains sequencing of the D1/D2 domain of the LSU rRNA gene was necessary. Selected members of each group were identified by amplifying and sequencing the D1/D2 region of the ribosomal RNA's large subunit coding gene.

Using this method, yeast strains of the Yarrowia group from raw meat, raw milk, cheese and cottage cheese were assigned to seven species. Four of them (Y. lipolytica, Yarrowia deformans, Candida galli and Candida alimentaria) are earlier described species, three of them proved to be novel ones and had been described as Y. divulgata [13], $Y$. porcina and $Y$. bubula [14]. Using conventional methods based on phenotypic characteristics probably many strains would 


Journal of
Universal Science
Online

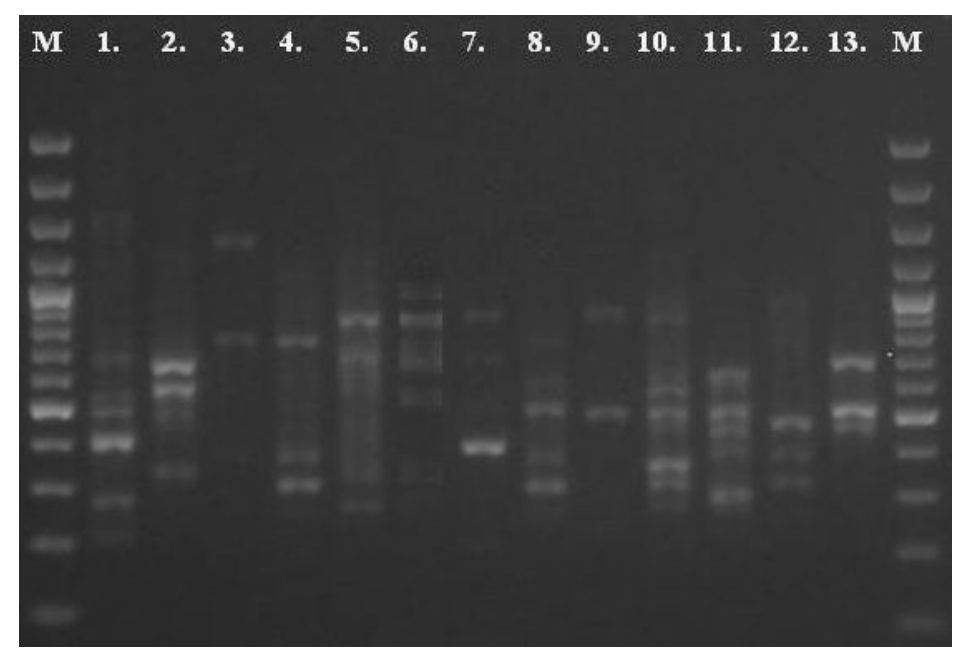

Fig 1. PCR fingerprints with the microsatellite primer $(\mathrm{GAC})_{5}$ from the type strains of the Yarrowia group.

M: Size marker (Thermo Scientific, Generuler 100bp SM0321); 1. Y. lipolytica NCAIM Y.00591 ${ }^{\mathrm{T}}$, 2. Y. deformans NCAIM Y.02005 ${ }^{\mathrm{T}}$, 3. C. galli NCAIM Y.01482 ${ }^{\mathrm{T}}$, 4. C. alimentaria JCM 10151 ${ }^{\mathrm{T}}$, 5. C. hispaniensis $\mathrm{NRRL}^{\mathrm{T}}$-5580 ${ }^{\mathrm{T}}$, 6.

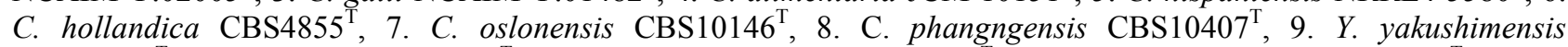
JCM12782 ${ }^{\mathrm{T}}$, 10. Y. divulgata F6-17 ${ }^{\mathrm{T}}$, 11. Y. porcina NCAIM Y.02100 ${ }^{\mathrm{T}}$, 12. Y. bubula NCAIM Y.01998 ${ }^{\mathrm{T}}$, 13. Y. $^{\text {. }}$ keelungensis CBS1 $1062^{\mathrm{T}}$.

have been misidentified as $Y$. lipolytica. Strains of the Yarrowia group could be successfully differentiated by using microsatellite PCR using $(\mathrm{GAC})_{5}$ primer. They formed seven clusters corresponding to the seven species identified by amplifying and sequencing the gene coding the D1/D2 region of the large subunit ribosomal RNA from some selected strains of each group.

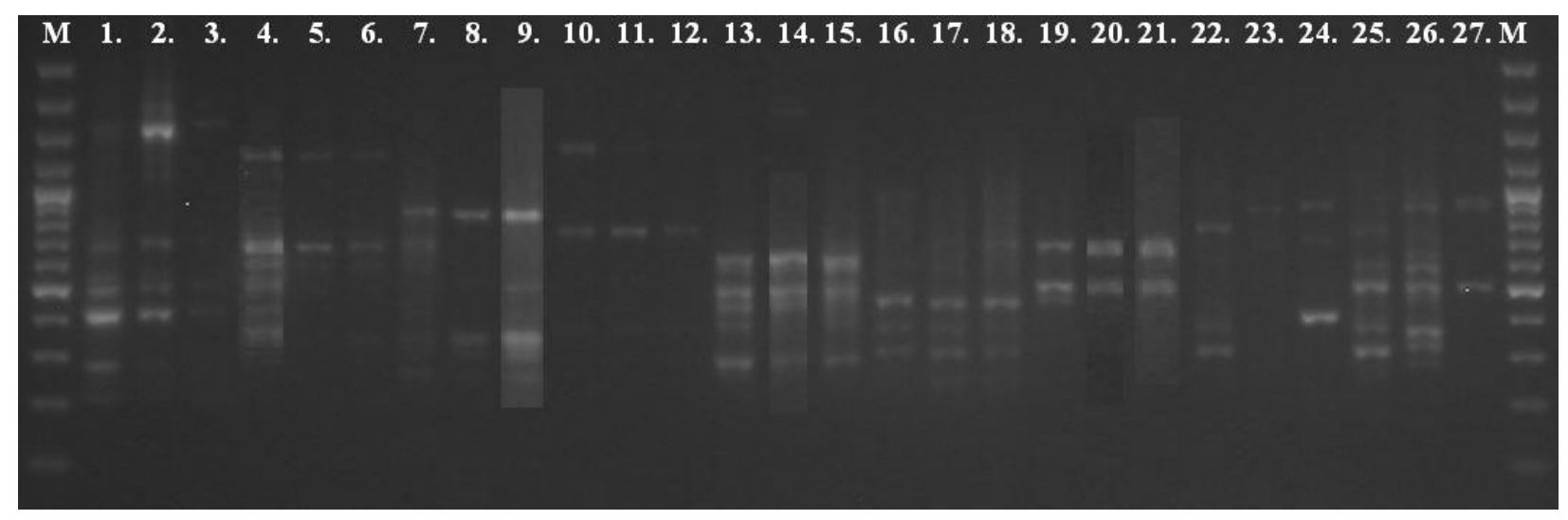

Fig 2. PCR fingerprints with the microsatellite primer $(\mathrm{GAC})_{5}$ from a few strains of the species of the Yarrowia group showing that this method is suitable to distinguish them.

M: Size marker (Thermo Scientific, Generuler 100bp SM0321); 1. Y. lipolytica NCAIM Y.00591 ${ }^{\mathrm{T}}$, 2. Y. lipolytica 148/4, 3. Y. lipolytica 854/4, 4. Y. deformans NCAIM Y.02005 ${ }^{\mathrm{T}}$, 5. Y. deformans 440/2, 6. Y. deformans 435/1, 7. C. alimentaria JCM 10151 ${ }^{\mathrm{T}}$, 8. C. alimentaria 440/1, 9. C. alimentaria 450/5, 10. C. galli NCAIM Y.01482 ${ }^{\mathrm{T}}$, 11. C. galli 437/3, 12. C. galli 435/4, 13. Y. divulgata F6-17 ${ }^{\mathrm{T}}$, 14. Y. divulgata 864/2, 15. Y. divulgata 862/1, 16. Y. porcina NCAIM Y.02100 ${ }^{\mathrm{T}}$, 17. Y. porcina 855/1, 18. Y. porcina 863/1, 19. Y. bubula NCAIM Y.01998 ${ }^{\mathrm{T}}$, 20. Y. bubula 855/3, 21. 863/1, 22. C. hispaniensis NRRL4-5580 ${ }^{\mathrm{T}}, 23$. C. hollandica $\mathrm{CBS}_{4855^{\mathrm{T}}}, 24$. C. oslonensis $\mathrm{CBS}_{10146^{\mathrm{T}}}$, 25. C. phangngensis $\mathrm{CBS}_{10407^{\mathrm{T}}}$, 26. Y. yakushimensis JCM12782 ${ }^{\mathrm{T}}$, 27. Y. keelungensis CBS11062 ${ }^{\mathrm{T}}$.T: type strain. 


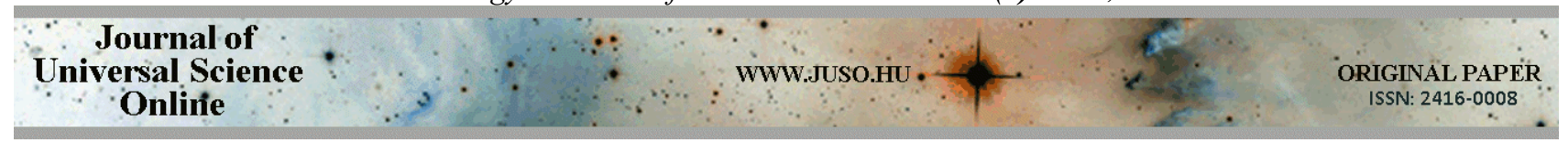

\section{Conclusions}

Microsatellite PCR can be an effective fingerprinting method for the differentiation, in some cases even for the identification of yeast strains. It can be useful to detect food spoilage yeasts, or even in tracing back the origin of spoilage outbreaks. However before using it the reliability of this method should be tested on the yeast species and strains wished to detect.
The food spoilage yeast strains of the Yarrowia group can be successfully differentiated by using microsatellite PCR fingerprinting method using $(\mathrm{GAC})_{5}$ primer, even their identity, thus their diversity can be assessed. However, additional sequencing is necessary for further evaluation the species specificity of the method.

\section{Acknowledgements}

This study was supported by the Doctoral School of Food Sciences, Corvinus University of Budapest. I am grateful to my collegues at National Collection of Agricultural and Industrial Microorganisms, namely Dr. Gábor Péter, Dr. Judit Tornai-Lehoczki, and Dr. Dénes Dlauchy for supervising me, Katalin Bétéri and Erika Brugovicz for technical assistance.

\section{References}

1. Baleiras Couto M.M., Hartog B.J., Huis in’t Veld J.H.J., Hofstra H., Van der Vossen J.M.B.M. (1996): Identification of spoilage yeasts in a foodproduction chain by microsatellite polymerase chain reaction fingerprinting. Food Microbioogy 13: pp. $59-67$.

2. Deák T. (2008): Handbook of food spoilage yeasts. $2^{\text {nd }}$ edition. Boca Raton: CRC Press. 325 p.

3. Ferreira A.D., Viljoen B.C. (2003): Yeasts as adjunct starters in matured Cheddar cheese. International Journal of Food Microbiology 86: pp. $131-140$.

4. Gardini F., Suzzi G., Lombardi A., Galgano F., Crudele M.A., Andrighetto C., Schirone M., Tofalo R. (2001): A survey of yeasts in traditional sausages of southern Italy. FEMS Yeast Research., 1:161167 .

5. Groenewald M., Boekhout T., Neuvéglise C., Gaillardin C., van Dijck P.W.M., Wyss M. (2013): Yarrowia lipolytica: Safety assessment of an oleaginous yeast with a great industrial potential. Critical Reviews in Microbiology, 40 (3):187-206.

6. Hoshino, A.A., Bravo J.P., Nobile P.M., Morelli K.A. (2012): Microsatellites as tools for genetic diversity analysis. In: Caliskan M. (Ed.), Genetic Diversity in Microorganisms. InTech, pp. 149-170.
7. Kurtzman C.P., Robnett C.J. (1998): Identification and phylogeny of ascomycetous yeasts from analysis of nuclear large subunit (26S) ribosomal DNA partial sequences. Antonie van Leeuwenhoek, $73: 331-371$.

8. Kurtzman C.P. (2011a): Yarrowia van der Walt \& von Arx (1980). 927-929. p. In: Kurtzman C.P., Fell, J.W., Boekhout T. (Szerk.): The Yeasts, a Taxonomic Study. $5^{\text {th }}$ edition, Amsterdam: Elsevier, pp 2080.

9. Kurtzman C.P., Fell, J.W., Boekhout, T., (2011b): Summary of species characteristics. In: Kurtzman C.P., Fell, J.W., Boekhout (Eds) The Yeasts, a Taxonomic Study. $5^{\text {th }}$ edition, Amsterdam: Elsevier, pp 2080.

10. Lachance M.A., Boekhout T., Scorzetti G., Fell J.W., Kurtzman C.P. (2011): Candida Berkhout (1923). 987-1278. p. In: Kurtzman C.P., Fell J.W., Boekhout T. (Szerk.): The Yeasts, a Taxonomic Study. $5^{\text {th }}$ edition, Amsterdam: Elsevier, pp 2080.

11. Lanciotti R., Vannini L., Chaves Lopez C., Gobbetti M., Guerzoni M.E. (2005): Evaluation of the ability of Yarrowia lipolytica to impart straindependent characteristics to cheese when used as a ripening adjunct. International Journal of Dairy Technology, 58:89-99. 


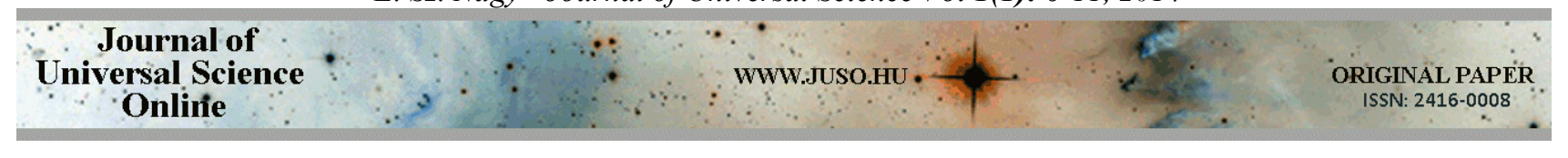

12. Mittal N., Dubey A.K. (2009): Microsatellite markers-A new practice of DNA based markers in molecular genetics. Pharmacognosy Reviews, 3:235-246. p.

13. Nagy E., Niss M., Dlauchy D., Arneborg N., Nielsen D.S., Péter G. (2013): Yarrowia divulgata f.a., sp. nov., a yeast species from animal-related and marine sources. International Journal of Systematic and Evolutional Microbiology, 63:48184823.

14. Nagy E., Dlauchy D., Medeiros A.O., Péter G., Rosa C.A. (2014): Yarrowia porcina sp. nov. and Yarrowia bubula f.a. sp. nov., two yeast species from meat and river sediment. Antonie van Leeuwenhoek, 105 (4):697-707.

15. Nagy, E. (2014): Isolation and diversity of food spoilage Yarrowia yeast strains from meat. Acta alimentaria, 3: 101-106

16. Patrignani F., Iucci L., Vallicelli M., Guerzoni M.E., Gardini F., Lanciotti R. (2007): Role of surface-inoculated Debaryomyces hansenii and Yarrowia lipolytica strains in dried fermented sausage manufacture. Part 1: evaluation of their effects on microbial evolution, lipolytic and proteolytic patterns. Meat Science, 75:676-686. p.
17. Patrignani F., Vannini L., Gardini F., Guerzoni M.E., Lanciotti R. (2011): Variability of the lipolytic activity and volatile molecules production by a strain of Yarrowia lipolytica in pork fat and its dependence on environmental conditions. Meat Science, 89:21-26.

18. Ramírez-Castrillón M., Mendes S.D.C., InostrozaPonta M., Valente P. (2014): (GTG) 5 MSP-PCR fingerprinting as a technique for discrimination of wine associated yeasts? PLOS ONE 9 (8): e105870.

19. Romano P., Capece A., Jespersen L. (2006): Taxonomic and ecological diversity of food and beverage yeasts. 13-54. p. In: Querol A., Fleet G. (szerk.) The Yeast Handbook Volume 2, Yeasts in Food and Beverages. Berlin Heidelberg: SpringerVerlag, 448 p.

20. Wyder M.-T., Bachmann H.-P., Puhan Z. (1999): Role of selected yeasts in cheese ripening: an evaluation in foil wrapped raclette cheese. Lebensmittel-Wissenschaft und Technology, 32:333343.

21. Zhang B., Rong C., Chen H., Song Y., Zhang H., Chen W. (2012): De novo synthesis of trans-10, cis12 conjugated linoleic acid in oleaginous yeast Yarrowia lipolytica. Microbial Cell Factories, 11: 51.pp. 